\title{
Sexual and Gender Identity Disorders
}

National Cancer Institute

\section{Source}

National Cancer Institute. Sexual and Gender Identity Disorders. NCI Thesaurus. Code C92202.

A category of psychiatric disorders characterized by a disturbance in sexual desire and in the psychophysiological changes that make up the sexual response cycle. 